REVIEW OF COMPARATIVE LAW

VOLUME XXVIII

YEAR 2017

\title{
LEGAL ASPECTS OF CLINICAL TRIALS IN POLAND
}

\author{
Katarzyna Syroka-Marczewska*
}

\begin{abstract}
A clinical trial is each trial conducted in humans to discover or confirm the clinical, pharmacological, including pharmacodynamic, effects of action of one or more investigational medicinal products, or to identify the adverse reactions to one or more investigational medicinal products, or to monitor absorption, distribution, metabolism and excretion of one or more investigational medicinal products, taking into consideration their safety and efficacy. It ought to be remembered that clinical trials may be conducted with the use of medicinal products. Clinical trials must be conducted in a way which is in line with the primary principle that clinical trial participants' rights, safety, health, and welfare override the interest of science and society.
\end{abstract}

Key words: clinical trials, medicinal product, pharmacovigilance, pharmaceutical law

\section{INTRODUCTORY REMARKS}

Medicines should, above all, be designed to protect human health and life. According to the definition, the term medicinal product ${ }^{1}$ denotes any

* Institute of Criminal Law, Faculty of Law and Administration, University of Warsaw, katarzynasyroka@gmail.com .

1 More on the definition of a medicinal product may be found in: Olszewski Wojciech L. (ed.) Pharmaceutical Law. Commentary, Warsaw 2016, Kondrat Mariusz (ed.) Pharma- 
substance or combination of substances presented as having properties for treating or preventing disease in human beings or animals; or which may be administered either with a view to restoring, correcting or modifying physiological functions of the organism by exerting a pharmacological, immunological or metabolic action, or to making a medical diagnosis ${ }^{2}$. Only the medicines which underwent clinical trials and which have been granted a marketing authorisation may enter the market.

A clinical trial is each trial conducted in humans to discover or confirm the clinical, pharmacological, including pharmacodynamic, effects of action of one or more investigational medicinal products ${ }^{3}$, or to identify the adverse reactions to one or more investigational medicinal products, or to monitor absorption, distribution, metabolism and excretion of one or more investigational medicinal products, taking into consideration their safety and efficacy ${ }^{4}$. It ought to be remembered that clinical trials may be conducted with the use of medicinal products ${ }^{5}$. The definition referred to above (stipulated in the national law) corresponds to the European Union

ceutical Law. Commentary, Warsaw 2016, Ł. Sławatyniec (ed.), Pharmaceutical Law Medicines Reimbursement, Warsaw 2013, M. Siwiec, Differences Between Medicinal Products, Food Supplements, Medical Devices and Foodstuffs for Particular Purposes. Practical Commentary, LEX on-line.

2 The definition of medicinal product is stipulated in Article 2 Point 32 of the Act of $6^{\text {th }}$ September 2001, Pharmaceutical Law, Journal of Laws Dz.U. 2008.45.271 as amended.

${ }^{3}$ An investigational medicinal product is a substance or a combination of substances, which have been given an active substance or placebo pharmaceutical form, studied or used as a reference product in a clinical trial, including also a product already authorised for marketing but used or prepared differently than the form authorised for marketing, or used in a non-authorised indication, or used to obtain additional information concerning the forms which have already been authorised for marketing (Article 2 Point $2 \mathrm{c}$ of the Act of $6^{\text {th }}$ September 2001, Pharmaceutical Law, Journal of Laws Dz.U. 2008.45.271 as amended, hereinafter "PhL").

${ }^{4}$ he definition of clinical trial is stipulated in Article 2 Point 2 of Pharmaceutical Law.

5 In accordance with Article 2 Point 3 of the Act of 20th May 2010 on Medicinal Devices, Journal of Laws 2015.876 as amended, a clinical investigation is a designed and planned systematic investigation in human subjects intended to verify safety or the effects of a certain medicinal product, accessories of a medicinal product or an active implantable medical device. 
Regulations i.e. to the Directive $2001 / 20 / \mathrm{EC}^{6}$ of the European Parliament and of the Council.

Clinical trials are conducted in four phases (stages). Each phase needs to end with a positive result in order to be able to move on to the next one. First, the safety of a given active substance is preliminarily assessed together with its metabolism, absorption, excretion, possible toxicity, and interactions with other substances used by the patient. Following that, it is possible to determine the dosage of the substance tested ${ }^{7}$. The second phase aims at determining whether the medicine brings results in a group of patients and whether it is safe for them. At this stage, the effects of the new medicine and placebo or the medicine used in the treatment of a given disease, are compared. The comparison is performed with the use

${ }^{6}$ Directive 2001/20/EC of the European Parliament and of the Council of 4 April 2001 on the approximation of the laws, regulations and administrative provisions of the Member States relating to the implementation of good clinical practice in the conduct of clinical trials on medicinal products for human use (hereinafter: "Directive 2001/20/ EC”). At this point, Regulation 536/2014 of $16^{\text {th }}$ April 2014 on clinical trials on medicinal products for human use, and repealing Directive 2001/20/EC should be mentioned. The Regulation shall apply as from six months after the functionality of the EU portal and EU database has been verified, yet in any event no earlier than $28^{\text {th }}$ May 2016. Due to delays related to portal development works it is currently estimated that the regulation will apply not earlier than from January 2017. As M. Mąkosa puts it: "new EU Regulations eliminate certain procedural differences between countries and Poland may benefit from this situation. At the same time, the areas left to be regulated by national systems or not stipulated in the regulation together with established practice (related, among other things, to the interpretation of the Regulation) will constitute the aspect which differentiates EU members. Taking the opportunities created by the Resolution, depends on the quality of legal and organisational environment which is to be formed by Polish legislators. It is necessary to comprehensively analyse the scale and scope of required approximations; the new system will not work without further regulation of certain issues. Lack of proactive attitude of the legislator in the approximation activities may result not only in Poland losing the opportunity to boost research market, but also in direct limitation of the number of researches conducted and creating opportunities for other countries of the region. Legislator and stakeholders' proactive attitude in the above-mentioned scope may have a positive impact on the innovativeness of the health care system in Poland.”, M. Mąkosa, Expected impact of Regulation 536/2014 on clinical trials in Poland, http://www.badaniaklinicznewpolsce.pl/ konferencja-badania-kliniczne--nowe-otwarcie/.

7 In the case of research concerning substances used in cancer treatment the $1^{\text {st }}$ and the $2^{\text {nd }}$ phase are combined so as not to expose healthy volunteers to highly toxic substances. 
of the blind study method, which is supposed to ensure the most objective evaluation of the effects possible ${ }^{8}$. The next phase is the trial conducted in numerous groups of participants with a view to determining the safety and therapeutic efficacy of the new medicinal product in relation to a particular disease and, where possible, with the employment of double-blind study method and random selection of participants (randomisation) ${ }^{9}$. Such trial is intended to enable the determination of the incidence of occurrence of the most frequent adverse effects and factors modifying the potency of action of the product ${ }^{10}$. After successful completion of phase three of the clinical trials, the medicine may be registered and marketed. Taking into account the registration procedure and the territorial coverage, two types of authorisations may be distinguished, namely, marketing authorisations issued at the community level under Regulation 726/2004 ${ }^{11}$ and authorisations issued on the basis of national regulations and valid only in the territory of the issuing state. Importantly, national authorisations may be also issued within the scope of procedures coordinated in the European Union i.e. mutual recognition procedure and decentralised procedure. Therefore, medicinal products which may be marketed are those which have been granted a marketing authorisation by the Council of the European Union or European Commission in the case of community-level authorisation, or by the President of the Office for Registration of Medicinal Products, Medical Devices and Biocidal Products (hereinafter referred to as the "President of the Office") in the case of national-level authorisation. The authorisation issued by the President of the Office applies to medicinal products which are to be used solely in the territory of Poland

${ }^{8}$ In this methods, neither the patient, nor the researcher knows if the patient is given the investigational substance or placebo. The group of people taking part in the research is chosen randomly and comprises several hundred volunteers, including patients suffering from a given disease, http://www.badaniaklinicznewpolsce.pl/o-badaniach-klinicznych/ podstawowe-informacje/jak-sie-prowadzi-badania-kliniczne/ visited on $27^{\text {th }}$ April 2017.

9 M. Czarkowski, J. Różyńska, Informed consent to participate in a medical experiment. Researcher's Guide, Warsaw 2008, p. 19.

10 Ibidem.

11 Regulation EC 726/2004 of the European Parliament and of the Council of $31^{\text {st }}$ March 2004 laying down community procedures for the authorisation and supervision of medicinal products for human and veterinary use and establishing a European Medicines Agency (Dz.U. UE.L. 04.136.1). 
and medicinal products which were subject to European procedures within the mutual recognition and decentralised procedure framework. In the case of the said European procedures the President of the Office grants authorisation in accordance with accepted assessment report and medicinal product Characteristics, leaflet and package labelling. For products to be marketed only in the territory of Poland, the President of the Office is the authority issuing the marketing authorisation and accepting the wording of the medicinal product Characteristics, leaflet, and package labelling which constitute integral elements of the authorisation. For medicinal products and veterinary medicinal products which were subject to the so-called centralised procedure conducted by EMA ${ }^{12}$ in London, the marketing authorisation is issued by the Council of European Union or the European Commission.

Once a medicinal product in marketed, its safety and efficacy continue to be monitored. The final phase of the clinical trials concerns medicines which are already marketed and its objective is to verify whether the medicine is safe in all indications given by the producer and for all groups of patients. In the course of this phase, the results of the previous phases are additionally verified.

Pharmacovigilance consist, above all, in collecting and analysing information on adverse effects. Each medicinal product may cause an adverse effect which is defined by WHO as a response to a medicine which is noxious and unintended, and which occurs at doses normally used in man for the prophylaxis, diagnosis, or therapy of a disease. The effects in question have been classified into six basic types ${ }^{13}$. Adverse effects type A (augmented) are directly related to the dose and the reaction of the organism to the active substance. In most cases they are predictable as they are connected with the medicinal product effect mechanism. According to W. Masetbas, they are characterised to rapidly subside upon discontinuation of the medicinal product ${ }^{14}$. The next category are adverse effects type B (bizarre) which are independent of the medicine dose. Most frequently they are

12 European Medicines Agency

13 Pharmacovigilance, I. Łagocka, A. Maciejczyk (ed.), Warsaw 2008.

${ }_{14}$ W. Masełbas, Adverse Drug Reactions: definitions, causes, classification, [in:] Pharmacovigilance, I. Łagocka, A. Maciejczyk (ed.), Warsaw 2008, p. 72. 
allergic or pseudoallergic reactions and therefore cannot be predicted. Adverse effects type $\mathrm{C}$ (chronic use) are those related to chronic administration of a given medicinal product and include drug-induced diseases as well as addictions. There exist also unintended and delayed adverse effects of medicines, the so-called adverse effects type D (delayed). They result to be detrimental to patient's health and appear after a few months or even years of medicine administration. Type E adverse effects (end of use) are caused by withdrawal. The last category of adverse effects is type $\mathrm{F}$ (failure of therapy) and concern the situations where the treatment applied is inefficient. Regardless of the categories, it is worth emphasising, that adverse effects of medicinal products result in a tremendous variety of symptoms. Certain effects of some medicines appear only after their interaction with other medicinal products. There are also situations, where a medicinal product of high toxicity transpires to be the only one which can be applied in a given disease. Such decisions require acute awareness of both parties. Medicinal products may also cause severe adverse effects which irrespectively of the administered dose result to be lethal, or to pose threat to a patient's life, require inpatient hospitalisation, or results in persistent or significant disability. In view of the foregoing, the safety of pharmaceuticals which have been authorised for marketing is of utmost importance. Marketing authorisation holder is obligated to indicate a person responsible for pharmacovigilance. The duties of the responsible person include conducting ongoing assessment of data in the post-registration period as well as remaining vigilant about information which could imply the necessity to undertake extraordinary measures ${ }^{15}$. Moreover, under Directive 2010/84/EU of the European Parliament and of the Council of $15^{\text {th }}$ December 2010 amending - in the scope of pharmacovigilance - Directive $2001 / 83 / \mathrm{EC}$ on the Community code relating to medicinal products for human use, patients, their statutory representatives, and de facto carers have been empowered to directly report adverse effects of medicinal products which they experienced or which they observed in third parties.

To date, from the legal perspective only the descriptions of cases confirmed by a professional healthcare employee were considered

15 A. Maciejczuk, A. Arcab, Pharmacovigilance - legal provisions, [in:] Pharmacovigilance I. Łagocka, A. Maciejczyk (ed.), Warsaw 2008, p. 47. 
valid. The amended provisions of the Pharmaceutical Law Act aiming at transposition of the provisions of the above-cited Directive and thus improvement of pharmacovigilance, includes numerous new solutions, such as for instance, extending the group of persons entitled to file descriptions of adverse effects ${ }^{16}$. In accordance with Article 12a of the Act on Patients' Rights and Commissioner for Patients' Rights ${ }^{17}$ a patient or their statutory representative or de facto $\operatorname{carer}^{18}$ have the right to report any adverse effects of a given medicinal product to persons performing medical professions, the President of the Office for Registration of Medicinal Products, Medical Devices and Biocidal Products, or entity responsible for marketing the medicinal product. Notification of a single case of an adverse effect of a medicinal product to the President of the Office for Registration of Medicinal Products, Medical Devices and Biocidal Products must include: initials, sex or age of the patient concerned, name and surname of the reporting person, if report is filed by a person performing a medical profession, address of the place where the profession is practiced, signature of the reporting person provided that the notification is not sent electronically. The data pertaining to the medicinal product which must be included in the notification are as follows: name of the product the application of which probably causes the adverse effect and a description of the adverse effect itself. The notification may be reported with the use of the form available at the website of the Office for Registration of Medicinal Products, Medical Devices and Biocidal Products.

The decision on introducing the possibility of notifying single cases of adverse effects by patients themselves or their representatives or carers was based on long-term observations and special pilot projects conducted in a few countries (Great Britain, Holland, Scandinavian countries). Programmes encouraging patients to be active in this field have proven that

16 The obligation of reporting adverse effects imposed on physicians, dentists, pharmacists, nurses, and midwives, as well as on paramedics, feldshers, and laboratory diagnosticians constitutes a correlative of this law.

${ }^{17}$ Act of $6^{\text {th }}$ November 2008 on Patients' Rights and Commissioner for Patients' Rights, Journal of Laws 2016.186.

18 In accordance with Article 3 of Act on Patients' Rights and Commissioner for Patients' Rights, a de facto carer is a person, having no statutory obligation yet performing constant care of a patient who, due to age, health or mental state, requires such care 
information provided in such a way is supplementary to the data provided by physicians or pharmacists. Moreover, it has been demonstrated that patients are first, before the physicians, to report new, adverse effects which have not yet been described. D. Karkowska aptly notices that thanks to the introduction of this solution, the role of patients has been emphasised as persons being the direct source of information on the appearance of an adverse effect of a medicinal product ${ }^{19}$.

\section{RULES FOR CONDUCTING CLINICAL TRIALS}

The general principle governing clinical trials is patient's welfare which should override the interest of science and society ${ }^{20}$. As U. Drozdowska pertinently observes, the right to physical and mental integrity must be respected, which means there is no room for pressure ${ }^{21}$. In accordance with Article 37 e $f$ the Pharmaceutical Law, except for clinical trials conducted in adults who can independently grant their informed consent and healthy clinical trial subjects, no incentives or financial gratifications except for reimbursement of costs can be used in clinical trials. The reimbursement of costs borne may cover the commuting expenses related physician's appointments, which usually are far more frequent than those mentioned in the clinical trial report, costs of meals which the patient needs to buy having arrived for tests with an empty stomach and stayed throughout the day in the healthcare centre, cost of additional medicine the application of which is required in the clinical trial report and which are not provided by the trail sponsor, as well as possible compensation for lost earnings ${ }^{22}$.

Another rule constituting a prerequisite of lawful clinical trials in Poland is the patient's consent. Consent may be defined as a statement of

19 D. Karkowska, Act on Patients' Rights and Commissioner for Patients' Rights. Commentary, LEX on-line, commentary to Article 12a, paragraph 3, sentence 5.

${ }^{20}$ U. Drozdowska, Consent of medicinal product clinical trial participant, [in:] M. Śliwka (ed.), An Outline of Clinical Trials Law, Torun 2013, p. 18.

21 Ibidem.

22 W. Masełbas, [in:] M. Kondrat (ed.), Pharmaceutical Law. Commentary, Warsaw, 2009. 
intent made freely and expressed according to the rules related to terms and meanings available to other participants of the medical process by a patient or their statutory representative on the basis information on all phases of the medical procedure.

Under legal theory ${ }^{23}$, for a patient's consent to be valid and expressed in a legally binding manner, the following conditions need to be fulfilled jointly: the consent must be expressed by an entitled person; the subject matter of the consent may be only such a right which may be freely disposed of by the parties ${ }^{24}$, the action being the subject matter of the consent must not infringe acts or community life principles, the consent must be expressed in a form stipulated by the legislator for a given category of activities, patient's consent must be preceded by appropriate information, the consent must be expressed consciously and voluntarily which means the patient has not acted under duress or error, and the consent must be expressed in an unequivocal manner which does not give rise any doubts.

Informed consent of clinical trial participant ought to be expressed in writing, dated and signed with a decision to take part in clinical trial taken freely after being duly informed on the nature, significance, implications, and risks related to the clinical trial; it should moreover be appropriately documented by a person capable of making a statement of consent and in the case of a person incapable of making a statement of consent, by their statutory representative. If a patient is not able to write, they may, in exceptional cases provided for in domestic regulations, express their consent orally in the presence of at least one witness.

Polish domestic regulations are compliant with Directive 2001/20/EC and also define informed consent as a decision, which must be written, dated and signed, to take part in a clinical trial, taken freely by any person capable of giving consent or, where the person is not capable of giving consent, by their statutory representative. Such consent includes a state-

23 B. Janiszewska, Patient's Welfare or Patient's Will - legal and medical dilemma (remarks on refusal to give consent to treatment and admissibility of living will statements), Law and Medicine no 2, 2007, pp. 33-45; J. Ignaczewski, Patient's Consent to Treatment, Warsaw 2003, p. 19 et seq.; M. Świderska, Patient's Consent to Healthcare Intervention, Toruń 2007 p. 45.

24 A. Szpunar, Consent of an entitled person in the scope of personal rights protection, Legal, Economic and Sociological Gazette no 1, 1990, p. 46. 
ment that it is taken after being duly informed on the nature, significance, implications, and risks related to the clinical trial.

As it has already been mentioned above, before receiving the informed consent the investigator ${ }^{25}$ provides the clinical trial participant or their statutory representative, orally or in writing, with information on the trial in a clear manner which is free of any duress. The information should concern in particular the nature, character and objective of the clinical trial, treatment applied in the clinical trial, and rules of random selection of participants, period of time during which the participant will take part in the trial, estimated number of participants, and duties of clinical trial participant. Moreover, a participant should be informed on predictable risks and inconveniences ${ }^{26}$, and compensation, or the possibility to treat the clinical trial participant in the case of loss incurred in relation to the participation in the clinical trial. In accordance with applicable regulations, investigator and sponsor are obligated to conclude an third party liability insurance agreement on the date of request for clinical trial commencement permission at the latest. Third party liability insurance covers investigator and sponsor's liability for causing bodily injury, health disorder or death of clinical trial participant resulting from policyholder's action or omission or action or omission of persons the policyholder is responsible for, during the period covered by insurance, caused in relation to the clinical trial ${ }^{27}$. The

25 An investigator is a physician, or a dentist if the clinical trial is related to dentistry, or a veterinarian in the case of a veterinary clinical trial, holding the professional licence in the territory of the Republic of Poland and adequately high professional qualifications, scientific knowledge and experience in work with patients, necessary for the conducted clinical trial or veterinary clinical trial, responsible for conducting these trials at a given centre.

If the clinical trial or the veterinary clinical trial is conducted by a team of persons, the investigator designated by the sponsor, with consent of the manager of the healthcare establishment within the meaning of regulations concerning medical activities, where the clinical trial is conducted, shall be the team manager responsible for conducting this trial at the given centre.

${ }^{26}$ It refers to inconveniences for a clinical trial participant or embryo, foetus, or breastfed infant.

27 In accordance with the Ordinance of the Minister of Finance of 30thApril 2004 on mandatory third party liability insurance of investigators and sponsors (Journal of Laws 2004.101.1034 as amended); the minimum guaranteed coverage sum of the third party liability insurance in relation to one and all events which are covered by the third party 
third party liability insurance does not cover damage consisting in damage, destruction or loss of property resulting from the development of addiction in clinical trial participant, if the participant was informed in writing about the possibility of addition upon commencement of the clinical trial, directly or indirectly caused by asbestos or related to it, or in payment of contractual penalties, damage resulting from war operations, martial law, riots and disorder, or acts of terrorism. In this context one should mention that current legal regulations provide for sponsor and investigator's faultbased liability and not strict liability, which undoubtedly makes pursuing claims more difficult for clinical trial participants. Mandatory third party liability is one of many ways of protection, yet the least beneficial for the aggrieved parties (the participants of clinical trial who suffered a health disorder ${ }^{28}$ ). This type of insurance requires from the aggrieved party to present evidence of policyholders' fault (investigator and sponsor's) or of persons' acting at their directions and remaining under their supervision. Furthermore, third party liability insurance is mainly of compensatory and not preventive nature and therefore it seems not to provide appropriate mechanisms enabling the insurer or policyholder to undertake measures aiming at eliminating the risk of damage occurrence (permanent health damage ${ }^{29}$. The above solution, which is currently applied, creates environment where persons taking part in clinical trials are practically deprived of insurance protection related to damage unpredictable from the current medical knowledge perspective, the so-called novelty risk, as first of all, the damage caused must be assigned to sponsor or investigator's fault and

liability agreement depends on the number of participants in a clinical trial who use investigational medicinal product or who are members of the reference group and amounts to the equivalent in PLN of:

1) EUR 500.000 - if there are 10 participants;

2) EUR 1.000 .000 - if there are 11 - 25 participants;

3) EUR 2.000.000 - if there are 26 - 50 participants;

4) EUR 4.000.000 - if there are 51-100 participants;

5) EUR 5.000.000 - if there are over 100 participants.

${ }^{28}$ A. Nurczyńska, Damage caused as a result of clinical trials in trail participant (patient) in the light of amended pharmaceutical law regulations, http://www.prawoimedycyna.pl/?str=artykul\&id=1037 .

29 W. Masełbas [in:] Pharmaceutical Law. Commentary. M. Kondrat (ed.), pp. 444 -445 . 
second of all, it must be proven. Planned legislative amendments intend to introduce strict liability where proving the responsibility of the sponsor or other persons is simpler for the aggrieved participant as they do not need to prove the fault of the entities, which surely is positive.

It should be stressed that the information which clinical trial participant should be provided with needs to include also the form of payment ${ }^{30}$ for the benefit of clinical trial participant as well as expected costs ${ }^{31}$ which the participant may bear in relation to the clinical trial. Additionally, the participant must be aware of the principle of voluntary participation and the possibility to refuse and withdraw from clinical trial at any time without any damage or loss of profit to which the participant is entitled for other reasons, of the requirement to express written consent for making source documentation concerning the participant available to entities authorised to conduct pharmacovigilance, audit, or inspection of the clinical trial, of the requirement to express written consent to grant investigator access to medical documentation concerning clinical trial participant drawn up before the commencement of the clinical trial, and of the requirement to express their consent to process personal data of the clinical trial participant related to their involvement in clinical trial, of confidential nature of the part of clinical trial documentation which would enable the identification of the clinical trial participant, as well as of the exclusion of personal data in possible publications of clinical trials results, and of the fact that any new data on clinical trial which may influence the participant's will to continue their further involvement in the trials shall be immediately communicated to the clinical trial participant or their statutory representative. The information the participant must be provided with should moreover include data pertaining to the contact person who may furnish further details on the clinical trial, clinical trial participants' rights and reporting possible damage caused in relation to the participation in clinical trial. The participant also must be informed about predictable circumstances and reasons for which the participation in clinical trial could be discontinued ${ }^{32}$.

30 If anticipated.

31 If anticipated.

32 Ordinance of the Minister of Health of $2^{\text {nd }}$ May 2012 on Good Clinical Practice, Journal of Laws 2012.489. 
The information referred to above must not include any suggestions concerning the waiver of any rights by the clinical trial participant or exempting investigator or sponsor from trail-related liability.

In contrast to Directive 2001/20/EC, Polish legislator, in situations where informed consent may not be expressed in writing, requires the presence of at least two witnesses for an oral consent to be considered val$\mathrm{id}^{33}$. The literature on the subject suggests the witness should each time be an outsider, in other words, a person not involved in any way in the clinical trial who has full capacity to make acts in the law ${ }^{34}$. A person who is somehow interested in conducting a clinical trial should not be a witness ${ }^{35}$. What is more, the witness should act with due discernment and be aware of the significance of their role ${ }^{36}$.

Apart from the consent expressed personally by the clinical trial participant, there exists another type of consent which is equally valid, namely, surrogate consent ${ }^{37}$ given by statutory representative of a fully incapacitated person or by guardianship court. Yet another form of granting consent in parallel consent in the case of, for instance, a minor who attained the age of 16 or who has not attained this age, but is able to express their opinion on the participation in clinical trial with due discernment.

In the case of clinical trial with the participation of a fully incapacitated person, the informed consent concerning the person's participation in clinical trial is to be granted by the person's statutory representative, and in the situation where the person in question is able to express their opinion on the participation in clinical trial with due discernment, a written consent of the person is additionally required. When the person participating in clinical trial has full capacity to make acts in the law who is unable to express their opinion on the participation in clinical trial, informed con-

\footnotetext{
33 As indicated above, the Directive mentions at least one witness.

34 W. Masełbas [in:] Pharmaceutical Law. Commentary. M. Kondrat (ed.), Warsaw 2009, p. 458.

${ }^{35} \mathrm{~J}$. Haberko, Witness to consent for diagnostic and therapeutic activities comprising medical experiment in the light of Act on the professions of Doctor and Dentist and Pharmaceutical Law, Law and Medicine 2009, no 3, p. 73.

36 Ibidem.

${ }^{37}$ Detailed analysis of surrogate consent remains beyond the scope of the present study.
} 
sent for the person's participation in clinical trial is issued by guardianship court with jurisdiction over the clinical trial site. There is an additional aspect of this issue, namely, the persons enumerated above must not undergo clinical trials if the persons having full capacity to make acts in the law knowingly refused to participate in the trials.

The literature on the issue indicates the problem of assessing the consent granted by a clinical trial participant in a situation where the said participant's financial situation is truly arduous which raises the question whether such consent was of free nature. "Free" in the context denotes an action of free will, undertaken in an uninhibited, free and natural manner; therefore one should determine whether the offer of gaining certain profits in relation to the participation in clinical trial does not distort the freedom of the decision-making process ${ }^{38}$. In extreme situations it appears to be possible to question a consent due to a defect in the declaration of intent referred to in Article 82 of Polish Civil Code which stipulates that a declaration of intent made by a person who, for any reason, is in a state which precludes the conscious or free making of a decision and declaring of intent is invalid.

A final remark which needs to be made on this subject is that there are additional requirements laid down by the legislator in relation to certain categories of clinical trial participants, and so clinical trial with the participation of minors may be conducted provided that the following conditions are met: informed consent of statutory representative and the minor has been granted in a way compliant with the regulations set forth by the legislator; the clinical investigator, or the person indicated by the clinical investigator having experience with minors, has provided the minor with comprehensible information regarding the clinical investigation and the related risk and benefits; there will be direct benefits for the group of minor patients from the clinical trial, and such investigation is essential to validate data obtained in clinical trials in persons able to give informed consent, or in clinical trials conducted with the use of other research methods; the clinical trial directly addresses a disease in a given minor or it can be conducted only with the participation of minors. Moreover, clinical trial ought to be designed to minimise pain, fear and any other foresee-

38 R. Kubiak, Experiment Participant Consent, Law and Medicine 2000, no 8, p. 53. 
able risk in relation to the disease and age of the minor. The situation of a fully incapacitated person has been regulated in a similar manner and they may take part in clinical trial provided that: the person has received information, according to their capacity of understanding, on the clinical investigation and trial-related risks and benefits; the wish of a person, who is capable of forming an opinion and assessing the information, to refuse participation in, or to be withdrawn from, the clinical trial is to be accepted by the clinical investigator at any time; such clinical trial is essential to validate data obtained in clinical trials in persons able to give informed consent, and relates directly to a life-threatening or debilitating condition of the person concerned; the clinical trial has been designed to minimise pain, fear and any other foreseeable risk in relation to the disease and the age of the patient; and finally, there are grounds to expect that administering the medicinal product tested will be beneficial to the patient and will not involve any risk.

Each participant has the right to withdraw from the clinical trial at any time by revoking their informed consent.

Furthermore, over the years the standards of Good Clinical Practice (hereinafter GCP) have been developed the primary principle for which is that patients' welfare, rights and safety take precedence over the interest of science or society and the data obtained must be reliable and precise. GCP standards require that all clinical trials have scientific grounds and plan, the so-called clinical trial protocol which specifies the objectives and methodology of the trial, number of patients, participants selection criteria (for including and excluding), number of participants is particular groups, number of investigation centres, laboratory research, frequency of and actions performed during physician's appointments, conditions of trial discontinuation, safety procedures, rules concerning trial monitoring activities, and rules on drawing up the trial final report.

What guarantees the compliance with the principles and standards in relation to clinical trials is the operation of Bioethics Committee. The Bioethics Committee issues an opinion on the clinical trial upon request of the sponsor submitted along with the documentation constituting the basis for its issuance. In preparing the opinion the Bioethics Committee considers, in particular the following: the relevance, feasibility and plan of the clinical trial; the analysis of the anticipated benefits and risks; the cor- 
rectness of the clinical trial protocol; the suitability of the investigator and supporting staff members; the level and completeness of the written information to be given to the clinical trial participants; the correctness of the procedure to be followed for the purpose of obtaining informed consent, and the justification for the trial in persons incapable of giving informed consent; the level of damages or compensation in the event of injury or death attributable to participation in the clinical trial; the amounts of remuneration or compensation for the persons conducting the clinical trial and for clinical trial participants, and the clinical trial agreements concluded between the sponsor and the centre; and the regulations governing the clinical trial participants' recruitment process. Bioethics Committees not only ensure that the applicable regulations are observed, but also safeguard the compliance of projects with principles of clinical trials ethics.

\section{FINAL REMARKS}

Clinical trials must be conducted in a way which is in line with the primary principle that clinical trial participants' rights, safety, health, and welfare override the interest of science and society. As far as clinical trials market in Poland is concerned, $\mathrm{PwC}$ report presents it as continuously developing and showing further growth potential ${ }^{39}$. Between 2012 and 2014, there was a drop in the number of new clinical trial registrations, which can be attributed to a number of both local and global factors ${ }^{40}$. The authors of PwC 2015 report indicate above all the lengthy administrative procedures and a large number of formal requirements in Poland; less friendly regulations than in other European countries, where additional allowances and incentives are typically offered to clinical trial sponsors; implementation of the provisions of the Directive 2001/20, which has made EU countries less competitive vs. the rest of the world in the clinical

39 Report "Clinical Trials in Poland”, December 2015, (hereinafter: PwC 2015 report) http://www.pwc.pl/pl/pdf/badania-kliniczne-raport-pwc.pdf .

40 PwC 2015 report, p. 16. 
trials sector; and consolidation of the global pharmaceutical market and, consequently, a decrease in the number of sponsors ${ }^{41}$. In the same period, the costs of conduct of clinical trials increased due to growing complexity of clinical trials, resulting from e.g. increased diagnostic requirements; a drop in the percentage of patients ultimately enrolled to clinical trials (due to more detailed requirements concerning the type of ailment, resulting from a growing share of clinical trials of targeted therapies, one has to screen larger populations), which can hinder recruitment and lead to an increase in the number of sites required to reach the target number of patients; and an increase in formal requirements, generating additional $\operatorname{costs}^{42}$.

Regardless of the foregoing, it needs to be emphasised that the clinical trials market in Poland has various key advantages, which make it attractive for clinical trial sponsors and these include large population of patients and qualified medical staff. Additionally, research centres are specialised and well-organised. And last but not least, attractive level of clinical trial costs when compared to Western Europe or even some Central and Eastern Europe countries.

\section{REFERENCES:}

Czarkowski Marek, Różyńska Joanna, Informed consent to participate in a medical experiment. Researcher's Guide, Warsaw 2008, p. 19.

Drozdowska Joanna, Consent of medicinal product clinical trial participant, [in:] M. Śliwka (ed.), An Outline of Clinical Trials Law, Torun 2013, p. 18.

Haberko Joanna, Witness to consent for diagnostic and therapeutic activities comprising medical experiment in the light of Act on the professions of Doctor and Dentist and Pharmaceutical Law, Law and Medicine 2009, no 3, p. 73.

Ignaczewski Jacek, Patient's Consent to Treatment, Warsaw 2003, p. 19 et seq.; M. Świderska, Patient's Consent to Healthcare Intervention, Toruń 2007 p. 45.

\footnotetext{
${ }^{41}$ Ibidem.

${ }^{42}$ Oncology has remained the leading therapeutic area.
} 
Janiszewska Beata, Patient's Welfare or Patient's Will - legal and medical dilemma (remarks on refusal to give consent to treatment and admissibility of living will statements), Law and Medicine no 2, 2007, pp. 33-45.

Karkowska Dorota, Act on Patients' Rights and Commissioner for Patients' Rights. Commentary, LEX on-line, commentary to Article 12a, paragraph 3, sentence 5.

Kondrat Mariusz (ed.), Pharmaceutical Law. Commentary, Warsaw 2016.

Kubiak Rafał, Experiment Participant Consent, Law and Medicine 2000, no 8, p. 53.

Łagocka Iwona, Maciejczyk Agata (ed.), Pharmacovigilance, Warsaw 2008.

Maciejczuk Agata, Arcab Anna, Pharmacovigilance - legal provisions, [in:] Pharmacovigilance I. Łagocka, A. Maciejczyk (ed.), Warsaw 2008, p. 47.

Masełbas Wojciech, Adverse Drug Reactions: definitions, causes, classification, [in:] Pharmacovigilance, I. Łagocka, A. Maciejczyk (ed.), Warsaw 2008, p. 72.

Masełbas Wojciech, [in:] M. Kondrat (ed.), Pharmaceutical Law. Commentary, Warsaw, 2009.

Mąkosa M., Expected impact of Regulation 536/2014 on clinical trials in Poland, http://www.badaniaklinicznewpolsce.pl/konferencja-badania-kliniczne--no we-otwarcie/.

Nurczyńska Anna, Damage caused as a result of clinical trials in trail participant (patient) in the light of amended pharmaceutical law regulations, http://www. prawoimedycyna.pl/?str=artykul\&id=1037 .

Olszewski Wojciech L. (ed.), Pharmaceutical Law. Commentary, Warsaw 2016.

Sławatyniec Łukasz (ed.), Pharmaceutical Law Medicines Reimbursement, Warsaw 2013.

Siwiec M., Differences Between Medicinal Products, Food Supplements, Medical Devices and Foodstuffs for Particular Purposes. Practical Commentary, LEX on-line.

Szpunar A., Consent of an entitled person in the scope of personal rights protection, Legal, Economic and Sociological Gazette no 1, 1990, p. 46. 